\title{
Regulación, representación y experiencia del cuerpo deportivo femenino: Tres formas de ver a las mujeres en el ring
}

\author{
Catalina Delgado
}

Consultora independiente, Colombia c.delgado63@uniandes.edu.co

Resumen: El objetivo de este artículo es hacer un recorrido por la Antropología del Cuerpo que aborda la incursión de las mujeres en deportes tradicionalmente "masculinos", como el boxeo, y exponer las diferentes aproximaciones al tema. Las dos primeras secciones de este balance bibliográfico presentan el tema desde una perspectiva externa o "no participativa", exponiendo en la primera parte los mecanismos políticos que regulan los cuerpos de las mujeres en el deporte y mostrando en la segunda parte, las formas de representación, regulación y consumo de identidades en la sociedad capitalista. Por último, en la tercera sección se adoptará una perspectiva interna o "participativa", haciendo énfasis en la experiencia vivida como aprendizaje del cuerpo y como método para abordar las investigaciones sobre el cuerpo de las mujeres en el deporte

Palabras clave: Deporte, cuerpo, género, boxeo, embodiment.

Regulation, representation and experience of the female athletic body: Three ways of seeing the women on the ring

Abstract: The aim of this article is to summarize the literature on the sporting body in the field of Anthropology, with special regard on the incursion of women in the traditionally "masculine" combat sports such as boxing. The text is organized according to the different approaches to body and sports culture used by social scientists. The first two sections of our review of literature shall tackle this subject from an exterior perspective by exposing the various mechanisms regulating bodies in sports and by showing in which forms the sporting body is represented and depicted within a capitalist society. For the third part of this article, I shall adopt an internal perspective focusing on the lived experience as a learning process for the body and as an appropriate method for researching the sporting body.

Keywords: Sport, body, gender, boxing, embodiment.

Cuadernos de Antropología 2014, 24(2), 49-72

Recibido: 09-09-2014 / Aceptado: 15-10-2014

Revista del Laboratorio de Etnología María Eugenia Bozzoli Vargas

Escuela de Antropología, Universidad de Costa Rica

http://revistas.ucr.ac.cr/index.php/antropologia

ISSN 2215-356X 


\section{Introducción ${ }^{1}$}

El olvido del cuerpo ha sido recurrente en las distintas ramas de investigación de las Ciencias Sociales como la Antropología del Deporte, ya que desde un principio este se ha dado por sentado. Según Csordas (2000), antes del giro posmoderno en 1980, los estudios se referían al cuerpo exclusivamente como una entidad biológica. Mauss (1995) fue el primero en darle importancia al cuerpo, aunque en su teoría todavía se percibe una separación entre la persona y las técnicas del cuerpo. Después del giro reflexivo, Geertz (1973) propuso un enfoque más interpretativo, los estudios corporales se convirtieron en una preocupación etnográfica y a partir de los trabajos de Douglas (1966), el cuerpo se comenzó a considerar como un medio de expresión (Csordas, 2000). Sin embargo, esta mirada no consideraba el poder que las estructuras sociales tienen sobre el cuerpo.

Partiendo de esta premisa, Bourdieu recoge los trabajos de Mauss (1995) y Merleau-Ponty (1945), y reivindica el papel de la estructura social sobre el individuo (Besnier y Brownell, 2012). El cuerpo se convierte en un problema, una masa que recibe las imposiciones sociales (Csordas, 2000). En este enfoque el cuerpo se define como una construcción cultural, porque es el contexto cultural el que regula y significa las acciones internalizadas e incorporadas por el individuo.

En la última etapa que propone Csordas (2000), el cuerpo comienza a cobrar importancia como sujeto activo, ahora la cultura y el "yo" pueden ser comprendidos a través del embodiment. El cuerpo deja de ser un símbolo o una construcción de la estructura social y se convierte en fuente de conocimiento, revelando las tensiones y contradicciones de una sociedad; o las acciones e intereses que conforman las estructuras sociales y prácticas de resistencia (Eichberg, 2009). El cuerpo vuelve a ubicarse en el centro de la existencia humana y cambia su estatus de objeto por un rol más activo como mediador del conocimiento.

En lo que se refiere específicamente al cuerpo en los deportes de combate, Sánchez y Spencer (2013) afirman que su estudio puede aportar a las Ciencias Sociales en tres aspectos: violencia y género, etnicidad, y religión. En primer lugar, las artes marciales y deportes de combate implican un "agudo sentido de la gestión de la violencia", factor que además es considerado por García y Spencer como un "elemento diferencial en términos de género" (Sánchez y Spencer, 2013, p. 2). En segundo lugar, "estas actividades son sitios preferenciales para estudiar cuestiones de etnicidad y raza", ya que según los autores, estas actividades están relacionadas con "la migración y los intercambios culturales". Para finalizar, "las artes marciales y deportes de combate se pueden entender como un cierto tipo de religión secular [...] los regímenes ascéticos rodean algunas de estas prácticas e incluso la posibilida d de auto-transformación de los individuos" (Sánchez y Spencer, 2013, p. 4).

1 Artículo para optar al título de Magister en Antropología Social de la Universidad de los Andes, Bogotá, Colombia. Dirigido por el Profesor Juan Pablo Aranguren. Agradecimientos especiales a Lupe Rojas, Rafael Delgado, Camilo Torres y Roberto Salazar. 
Dentro de las Ciencias Sociales, el deporte se ha estudiado desde dos perspectivas teóricas distintas: la "funcionalista" y la de "conflicto". La "teoría funcionalista" argumenta que el deporte funciona en ventaja de quienes lo practican, "como el sistema es considerado justo, nada en esta teoría sugiere que las ventajas del deporte sean limitadas únicamente a los hombres"; por su parte la "teoría del conflicto" afirma que el deporte puede ser una fuente de "alienación y explotación que sirve a quienes están en el poder" (Hanson y Kraus, 1998, p. 94).

El objetivo de este escrito es hacer un recorrido bibliográfico por la Antropología del Cuerpo que aborda la incursión de las mujeres en deportes "masculinos", como el boxeo. Para esto, el artículo se ha divido en tres capítulos que corresponden a las diferentes aproximaciones utilizadas por investigadores sociales ${ }^{2}$ para abordar el tema de la corporalidad: el cuerpo político, donde se imponen las regulaciones deportivas corporales y se ejerce el control del cuerpo; el cuerpo social, constituido por las representaciones, usos y desusos del cuerpo en la sociedad capitalista; y el cuerpo individual, refiriéndose a la experiencia del "yo" vivida a través del deporte y al cuerpo como uno mismo.

Como se verá a continuación, los dos primeros capítulos “el cuerpo político y el cuerpo social” corresponden a una perspectiva externa que se enfoca en mostrar las imposiciones de la estructura deportiva sobre el cuerpo. En contraste, el tercer apartado "el cuerpo individual" adopta una perspectiva interna que reivindica las actividades corporales como formas de aprendizaje liberadoras. Por perspectiva externa, me refiero a investigaciones "no participativas" donde el autor adopta un punto de vista estrictamente exterior, y por perspectiva interna estoy haciendo alusión a trabajos "participativos" o vivenciales que incluyen un punto de vista interior en el análisis. Si bien las tres secciones de esta revisión bibliográfica recogen investigaciones de América Latina, Estados Unidos y Europa, se busca comparar o ilustrar estos trabajos con algunas observaciones sobre el boxeo femenino en Colombia.

\section{Cuerpo político: Regulaciones y control del cuerpo}

La exclusión de la mujer en el boxeo se adjudica a las diferencias físicas y culturales entre el cuerpo femenino y el masculino, lo que hace del boxeo un tema interesante de analizar desde la perspectiva corporal. En esta primera sección, se estudiará cómo y por qué el cuerpo de la mujer fue restringido de los deportes de combate, y cuál es el estigma social que pesa sobre las practicantes de estos deportes en la actualidad.

2 Estos tres niveles de análisis del cuerpo son propuestos por Scheper-Hughes y Lock en The mindful body: A prolegomenon to future work in medical anthropology (1987).

Cuadernos de Antropología 2014, 24(2), 49-72 


\section{La práctica deportiva como forma de control corporal y control de las relaciones de género}

En Corregir el cuerpo, Vigarello (2001) expone la importancia de los procesos de formación del cuerpo, debido a que este es el "primer lugar donde la mano del adulto marca al niño, es el primer espacio donde se imponen los límites sociales y psicológicos” (Vigarello, 2001, p. 98). Partiendo de esta idea, Douglas (1966) añade que estos procesos de formación se constituyen como formas de control corporal y por ende, como formas de control social (Douglas, 1966). Esto quiere decir que controlando las acciones del cuerpo, por ejemplo qué se puede hacer y cómo se debe hacer, se pueden regular los comportamientos del individuo en sociedad.

Para definir el fenómeno de las prácticas deportivas como formas de control de las relaciones de género, Huerta introduce el concepto de "deportivización", término ligado a la industrialización y a la consolidación del capitalismo. Este concepto se refiere a "la creación de nuevos tipos de mercancías como competencias, campeones y espectáculos"3 (Huerta, 2010, p. 308). En este contexto, los deportes practicados por mujeres se han relegado a un espacio marginal, las deportistas que practican las mismas actividades que los hombres son "desvaloradas, descalificadas, invisibilizadas y reducidas a los papeles genéricos de madres y esposas" (Huerta, 2010, p. 308).

El autor explica este fenómeno argumentando que la mujer representa una amenaza al "grupo juramentado" de los hombres (Huerta, 2010). Este término, introducido por Amorós, define a algunas esferas sociales, en este caso el deporte, como un espacio de socialización donde se refrendan actos patriarcales (Amorós, 2008). Las prácticas diferenciadas de las mujeres en los deportes amenazan el predominio que siempre han tenido los hombres en estas actividades. Por esta razón la "deportivización” intenta reducir esta amenaza ocultando a las mujeres, manteniendo así el dominio del patriarcado y las relaciones asimétricas de poder.

Además de ser invisibilizadas en el ámbito social, dentro de los espacios deportivos las mismas mujeres reproducen las formas de discriminación. En su artículo Ezzell (2009) muestra cómo en ciertos casos las deportistas que practican deportes vistos como "masculinos" y se enfrentan a los estigmas del público, "refuerzan y legitiman su identidad devaluada" (Ezzell, 2009, p. 115). "Defensive othering" es el nombre que le atribuye el autor a este tipo de comportamientos. En su investigación Ezzell descubre que las jugadoras de rugby se distanciaban de las identidades que pudieran poner en peligro su imagen femenina (como la de las mujeres lesbianas) y formaban entre ellas una identidad "heterosexy-fit" reforzando el "heterosexismo y la inequidad de género" (Ezzell, 2009, p. 115).

3 Las empresas de boxeo en Cartagena, encargadas de producir campeones son el ejemplo perfecto de este término: "en la empresa mía, mi apoderado había comprado la mitad de los derechos del contrincante que viste (Eduard Barrios). Después hubo una pelea y la empresa se dividió en dos y se lo llevaron a él. Cuando gané esa pelea, la empresa de ellos quebró (Víctor Llerena, Febrero 2014, comunicación personal).Pelea Llerena vs. Barrios 
Aunque este fenómeno parezca un problema actual, la reproducción de las inequidades de género por parte de las mujeres viene de tiempo atrás. En un artículo enviado por Gutiérrez al periódico colombiano El Gráfico en 1923, la deportista defiende la práctica diferenciada de actividades argumentando que los "sports deben ser seleccionados en cada caso para que den resultados racionales" (Gutiérrez, 1923). En este caso la autora utiliza el "defensive othering" de una forma más radical condenando la práctica de deportes varoniles por parte de las mujeres, porque según ella "natura dotó" a las mujeres de una sensibilidad especial que no se puede contradecir mediante la práctica de deportes "masculinos". Gutiérrez incita a las mujeres a practicar deportes como jiu-jitsu (técnica defensiva), tenis y natación; mientras que considera al boxeo como un deporte que podría hacer de la mujer "una sargentona".

Como se ha podido observar el control corporal también actúa como una forma de control social perpetrando imaginarios que ayudan a mantener las inequidades de género. En este caso, el deporte, la industria deportiva y hasta las mismas deportistas se han encargado de controlar los movimientos y las actividades físicas que les son permitidas a las mujeres.

\section{Regulaciones morales y control de la participación femenina en el deporte}

Desde 1830 se empezó a dar un cambio en el "modelo de mujer" y se impuso la "parisina", o la invención de la mujer activa. La belleza se acopló al nuevo modelo de ciudad, "en la urbe y sus elegantes avenidas, la mujer puede aspirar a la igualdad, sin que esta se pueda realmente realizar" (Vigarello, 2001, p. 66). Este modelo fue acogido en las diferentes esferas sociales, en el caso del deporte, se promovió la práctica deportiva entre las mujeres, la compra de ropa deportiva y la preocupación por el físico; aclarando que las participantes no podían aspirar al mismo nivel de competencia que los hombres.

Siguiendo el nuevo modelo de belleza de la mujer activa, a principios del siglo XX época en la que la cultura física estaba intrínsecamente ligada a la cultura moral (Pedraza, 1999), las mujeres en Colombia comenzaron a inscribirse en diferentes actividades deportivas como tenis, natación y esgrima (entre otros). Pero a diferencia de los hombres, los ejercicios se hacían con fines "reproductivos y estéticos" (Pedraza, 1999, p.165), las mujeres sólo podían practicar deportes para desarrollar el cuerpo de una manera "armoniosa, sin ponerlo en peligro" (Filina, 1923, p. 19).

Según Castañeda (2009), este tipo de restricciones sociales están ancladas a una concepción católica del cuerpo femenino donde "la contraparte de la virginidad es la maternidad. Por ella y para ella existe la sexualidad; por ella y para ella las mujeres poseen el cuerpo del cual fueron dotadas" (Castañeda, 2009, p. 78). La autora concluye afirmando que la historia del cristianismo es la historia de la diferenciación entre mujeres y hombres, garantizando la "naturalización" de la desigualdad "como una característica esencial in-modificable” (Castañeda, 2009, p. 78). 
En el caso de las mujeres que decidían practicar boxeo, los medios desaprobaban este tipo de prácticas "porque desfememinizaban el sexo y las despojaba de algunas de sus supuestas cualidades innatas como la prudencia, la suavidad y el decoro" y corrían el riesgo "de engolfarse en menesteres ajenos a su idiosincrasia" (Anónimo, 1925, p.10). Si bien ya existen regulaciones que permiten a la mujeres participar deportes tradicionalmente "masculinos", en países como Sur África se ha demostrado que la falta de participación en estos deportes se debe ahora a "factores sociales, como el rol ideológico de la mujer, la falta de incentivos, de seguridad y de instalaciones" (Burnett, 2001, p. 75).

Todavía se considera que la agresión es un atributo del hombre; y que la crianza es deber de la mujer, por lo tanto la boxeadora que trasciende este estereotipo "no puede ser tomada en serio" (Oates, 1987, p.117). A pesar de los avances legales que se han hecho por restablecer las condiciones de igualdad entre hombres y mujeres, la situación de in-igualdad entre los sexos persiste y "serán necesarias muchas revoluciones para que la belleza no se codifique más en el modelo de la mujer dominada, o del 'bello sexo"” (Vigarello, 2001, p. 66).

\section{Regulaciones del boxeo femenino, dentro y fuera del ring}

Durante el siglo XIX se empiezan a legitimar y regular los deportes de contacto como el rugby, el boxeo y el fútbol. Sin embargo, a las mujeres no se les permite participar legalmente, sino hasta del siglo siguiente. Más específicamente, durante la década de 1970 se da una convergencia de puntos de vista, según Guttman "algunas atletas se volvieron feministas y las feministas comenzaron a darle importancia al deporte" (Guttman, 1991, p. 209). Una de ellas fue la campeona de tenis Billie Jean Moffit King, quien comenzó a reclamar por la igualdad de los premios en los campeonatos de tenis. A partir de este ejemplo, otras deportistas comenzaron a replicar estas acciones de reclamo en diferentes ámbitos hasta lograr la igualdad de participación en el deporte.

En el caso del boxeo Las reglas de Queensberry se proclamaron en Inglaterra durante el año $1867^{4}$, y han regido la actividad pugilística masculina hasta el día de hoy. En cambio, el combate entre mujeres comenzó a prohibirse a medida que pasaba el tiempo, o se mantuvo como una actividad exótica presentada en las ferias para el entretenimiento de los espectadores, como se puede observar en un video registrado por Thomas Alva Edison a principios del siglo $\mathrm{XX}^{5}$.

Finalmente, en el año 1972 el congreso de los Estados Unidos aprobó el Título IX de las Enmiendas de Educación, donde se prohibía la discriminación sexual en cualquier programa educativo y la Asociación

4La historia del boxeo entre mujeres comienza en junio 23 de 1722, cuando el periódico London Journal reporta una pelea entre "dos del género femenino", que "mantuvieron la batalla con gran valor por mucho tiempo, para la gran satisfacción del público" (Guttman, 1991, p.75).

5 En este video se puede observar a las hermanas Gordon peleando en un escenario ambientado como un Jardín Francés. 
Mundial de Boxeo, estableció reglas específicas con respecto al boxeo femenino. Sin embargo, este reglamento se enfoca en acentuar y diferenciar el género, afirmando que las mujeres son diferentes a los hombres y que éstas no tienen las mismas capacidades deportivas. Para Guttman, "sólo en Cuba y Nicaragua, donde gobiernos comunistas han hecho un verdadero esfuerzo por democratizar la práctica deportiva, se han visto las verdaderas revoluciones en los deportes practicados por mujeres" (Guttman, 1991, p.236). Por ejemplo, en los juegos olímpicos de 1980 en Moscú, la cubana María Caridad Colón impuso un nuevo récord mundial de jabalina de 68,4 m. Esto demuestra que la diferenciación entre hombres y mujeres se hace a partir del trato, reflejado en las reglas deportivas.

Las reglas del boxeo tienen como propósito regular la violencia dentro el ring. Para Wacquant (2000), esta es una violencia paradójica, ya que en el ring el peleador gradualmente destruye aquello que más valora: su cuerpo. ¿Qué lleva entonces a los individuos a participar en estas actividades violentas? En el cuadrilátero, la violencia y el dolor tienen un propósito: en palabras de Pambelé, boxeador colombiano y campeón mundial, "quien se sube en un ring, expuesto a que le zafen la quijada con una trompada, debe apuntar hacia las metas más altas” (Salcedo, 2012, p. 102). El primer espacio donde se transgrede el límite de la violencia es durante el entrenamiento, en las sesiones de guanteo o sparring, "donde tiene que salir todo lo que se ha trabajado, todas las combinaciones [de golpes]" (Llerena, comunicación personal, febrero, 2014). El sparring es visto como una pelea de "entrenamiento" antes de saltar al combate real (amateur o profesional). Como en estas peleas no hay arbitro que haga cumplir las reglas, los contendores y los profesores deben regular los actos violentos.

En mi experiencia ${ }^{6}$, hacer sparring entre mujeres es aún más difícil. Durante el año que llevo entrenando en el gimnasio de boxeo, pocas mujeres se han subido conmigo a hacer sesiones de guanteo porque les da miedo pegarme, porque quieren mucho su nariz o porque no les gusta y prefieren únicamente golpear los sacos como forma de ejercicio. Las mujeres que sí deciden subir comienzan los primeros asaltos con miedo a excederse, pero golpe tras golpe el umbral de violencia comienza a aumentar ${ }^{7}$. Esto quiere decir

6 El tema de este balance bibliográfico surgió a partir de mi iniciación en el mundo del boxeo, y con el objetivo de complementar el artículo, decidí iniciar una investigación etnográfica paralela. Desde hace un año, asisto cinco (5) días a la semana a un gimnasio que promueve "hacer ejercicio, mientras se aprende boxeo". Dependiendo del entrenador, se enfatiza más en la primera o en la segunda parte. La mayoría de personas se inscribe para bajar de peso. Otros asisten porque ya boxeaban y quieren retomar sus entrenamientos cerca a sus lugares de trabajo o vivienda.

En general asiste una mujer a cada clase, donde llegan en promedio cinco hombres. La mayoría de mujeres se inscriben porque quieren bajar de peso y no les interesa el boxeo. Las mujeres que se comprometen a boxear amateur o profesionalmente entrenan en la liga colombiana de boxeo, donde el nivel es más alto.

Desde diciembre del 2013 el entrenador en el gimnasio es Víctor Llerena, campeón y exboxeador cartagenero. Él se ha enfocado en enseñarme sobre el deporte y la técnica del boxeo y la mayoría de apuntes etnográficos se han hecho durante este periodo.

7Antes de iniciar el guanteo, las participantes se advierten mutuamente "pasito", "sin darse duro". Cumpliendo la promesa los primeros asaltos son "suaves", pero llega un momento de descontrol, o profunda concentración, donde un golpe llega más fuerte que los anteriores. Si la contrincante decide responder el golpe con la misma potencia, comienza a aumentar el umbral de violencia.

Cuadernos de Antropología 2014, 24(2), 49-72 
que entre las mujeres que practican este deporte de una forma recreativa, existen reglas implícitas dentro del guanteo, probablemente formadas por imaginarios sociales que impiden a las mujeres actuar de forma natural en el ring.

Como lo señala Wacquant (2000), en el combate se está poniendo en juego aquello que más valoran, y más importante aún, lo que más creen que valoran los otros acerca de ellas: su cuerpo. Esta afirmación podría explicar la dificultad para encontrar una compañera de guanteo, o la falta de control o aceptación del aumento en el umbral de violencia. Las boxeadoras profesionales han quebrado estas reglas implícitas entre mujeres y han aceptado como mandamiento único, la ley del combate. ¿Qué lleva a estas mujeres a regirse por las leyes del deporte pugilístico y dejar de lado las normas sociales?

"Dinero, gloria, y respeto" (Salcedo, 2012, p. 51), a esto aspiran quienes se inscriben en el deporte de la violencia regulada de forma profesional. En el caso de las mujeres boxeadoras, quienes tienen que sufrir la discriminación y la marginalización social y económica del deporte, se aspira además de dinero y gloria, a ganar el respeto de hombres y mujeres dentro de la disciplina. Las boxeadoras quieren ser un ejemplo de superación, "no es sólo la lucha es más que eso: muchas mujeres pueden encontrar la fuerza en ver a otras mujeres luchar y aprender a ser fuertes, pueden encontrar algo allí que también tienen” (Lucia Rijker; en Bankowsky, 1999).

Como se ha visto a lo largo de la primera sección del artículo, los ideales corporales regulados por el ejercicio no son simplemente símbolos benignos de los valores sociales. Según Reischer y Koo (2004, p. 299) "los ideales del cuerpo sirven como mecanismos de poder y control social". Los principios morales, políticos y corporales aún vigentes, reflejan una heteronormatividad que ha constreñido a las mujeres en su práctica deportiva desde sus inicios hasta el tiempo presente. Sin embargo, en la época actual, estas reglas implícitas o explícitas ya no son presentadas en forma de obligación, la sociedad capitalista ha transformado estos deberes en deseos y necesidades.

\section{Cuerpo social: Representaciones y consumo del cuerpo deportivo en la sociedad capitalista}

Durante la segunda mitad del siglo XVIII, el boxeo fue promovido por conservadores y radicales ingleses con el fin de transmitir sus ideales políticos: en el caso de los conservadores el objetivo era preparar a las clases populares para la guerra e inculcar paternalismo y lealtad; mientras que los radicales utilizaron el boxeo como herramienta para empoderar a los trabajadores, enseñándoles sus obligaciones y sus derechos. El mismo cuerpo del boxeador podía ser percibido como un símbolo de constreñimiento o liberación. En el periodo histórico actual, regido por el sistema capitalista, el cuerpo todavía puede verse de estas dos 
maneras. Esta sección se enfocará en mostrar cómo el capitalismo ha logrado expandirse a través de un sistema de "identidades porosas", transformando el mercado en un sistema de consumo de identidades y controlando así los cuerpos. Sin embargo, como se verá en el último acápite, en medio de la expansión del sistema todavía pueden surgir algunas identidades alternativas que buscan liberarse de las imposiciones del mercado.

\section{El consumo de identidades corporales en la sociedad capitalista}

Durante el curso del siglo XX, el sistema capitalista constató la imposibilidad de crecer en una sociedad cerrada. Esto llevó al mercado a evolucionar de un sistema de inclusión/exclusión a una "estrategia de cooptación de identidades" (Bauman, 2007, p. 82). En el deporte esto se puede apreciar en los juegos olímpicos, fundados con el objetivo de "globalizar el gusto por el deporte y la competencia" (Gumbrecht, 2006, p. 24). La inclusión de diferentes deportes en el sistema global logró que individuos en diferentes partes del mundo empezaran a practicar estas actividades y a consumir productos deportivos específicos.

En la actualidad, los medios y el consumo producen individuos ya no a partir de "sistemas de sumisión visibles y explícitos [...] como en las sociedades arcaicas o precapitalistas" sino a partir de "sistemas de sumisión mucho más disimulados" (Guattari y Rolnik, 2005, p. 28) como la persuasión y el deseo. El deporte dejo de ser visto como obligación, y comenzó a ser presentado por los medios de una forma atractiva para el público, ejercicios para "verse bien y sentirse bien" o para salir de la rutina, "sutiles formas de dominación en la que la antigua norma dirigista o autoritaria es sustituida por las normas indicativas" (Citro et al., 2011, p. 122).

Para Gumbrecht (2006), el deporte ha conformado tres tipos de identidades a lo largo de su historia: los semidioses, los gladiadores o caballeros, y los rufianes. Estos estereotipos se pueden utilizar hoy para categorizar las identidades deportivas de los gimnastas y atletas (semidioses), los deportes en equipo (gladiadores o caballeros), y los deportes violentos (rufianes). Estas tres identidades definen los deportes, las actitudes, el comportamiento y el consumo, de aquellos que son persuadidos por el sistema a hacer parte de ellas. Las anotaciones de Gumbrecht (2006) permiten constatar que las tres identidades deportivas también representan tres estereotipos de masculinidad, lo cual hace más difícil la adopción o apropiación de estas identidades deportivas por parte de las mujeres.

Con el fin de adaptar el estudio del cuerpo y el deporte a la era global, Besnier y Brownell (2012) proponen utilizar el término body culture. Este concepto utiliza la cultura para contextualizar el cuerpo y la práctica en movimiento, es decir, el "movimiento corporal, movimiento emocional y movimiento social" de los cuerpos (Eichberg, 2009, p. 92). A partir de este concepto, el deporte deja de ser una práctica estática y se convierte en un fenómeno que se mueve y se transforma alrededor del globo y a lo largo del tiempo.

Cuadernos de Antropología 2014, 24(2), 49-72 
El cuerpo deportivo se puede analizar a través del consumo, asumiendo la corporalidad como un "producto cultural", con diferentes usos según sociedades y con diferentes valores, creencias y cánones estéticos asociados a él (Mauss, 1995, p.10). Este cuerpo es moldeado por la sociedad y llega a ser símbolo de la pertenencia, o de una posición dentro del orden social. En todo caso, el consumo permite al sujeto convertirse en "un «signo», un «mensaje» que habla de su propietario" (Buñuel, 1991, p.105).

En el contexto actual, el sujeto está librado a sí mismo y tiene la sensación y la posibilidad de ser único por medio de sus opciones de consumo. La transformación del individuo ya no consiste en satisfacer necesidades sino en "reconvertirse en producto, por medio de identidades compartidas en varios cuerpos" (Bauman, 2007, p. 82). Guattari y Rolnik acuñan el término de "agenciamientos de subjetivación" a estas opciones de consumo, y lo describen como procesos “descentrados en relación con la individuación” donde "la subjetividad está esencialmente fabricada y modelada en el registro de lo social" (Guattari y Rolnik, 2005, p. 46).

\section{La regulación del consumo de identidades deportivas femeninas}

Los medios que promocionan el consumo se convierten en reguladores sociales del tiempo libre, reforzando en el caso del deporte, los estereotipos de género que perpetúan la "superioridad masculina" y la "inferioridad femenina". En su artículo, Buysse y Sheridan (2004) hacen un estudio sobre las portadas de las revistas producidas por las organizaciones deportivas, donde concluyen que las mujeres que aparecen en las carátulas de las revistas son retratadas generalmente por fuera de la cancha, sin uniforme, o en posiciones pasivas. Esta afirmación se puede ejemplificar a partir de la portada de India today: Woman donde la campeona asiática Mary Kom se presenta con vestido largo y corona, sentada en una escalera, y con sus guantes al lado.

Las imágenes de portada de revistas pueden contrastarse con la serie de fotografías tomadas por Deliah Montoya, Women boxers: The new warriors (2006), donde se muestra la vida de boxeadoras profesionales dentro y fuera de la cancha. Al comparar estas dos imágenes (quién las patrocina, quién las hace, quién aparece y cómo aparece), es posible afirmar que el consumo promueve un único tipo de deportista femenina, que no siempre corresponde a la realidad.

Otra forma en la que los medios acentúan las desigualdades entre los sexos es a través del lenguaje. Messner descubre en su estudio que los narradores deportivos a menudo se refieren a las mujeres como "damas retratándolas como delicadas; o niñas, epíteto que las infantiliza" (Messner, 1993, p. 130). Para Guattari y Rolnik, la infantilización es una táctica de la "economía subjetiva capitalística", que permite a los dominantes "pensar por nosotros y organizar por nosotros la producción y la vida social" (Guattari y Rolnik, 2005, p. 56). 
Durante la investigación también se encontró que mientras los hombres son visualizados como agentes "activos en control de su destino", las mujeres son enmarcadas simplemente como objetos "reactivos" (Messner, 1993, p. 130). Por último, se concluyó que en los deportes de más contacto físico la infantilización es menos frecuente. Con respecto a este último hallazgo es necesario aclarar que en el boxeo sí se da una infantilización y una discriminación debido a la diferencia de fuerza entre hombres y mujeres, de ahí el dicho "pega como una niña"8. Este tipo de expresiones perpetúan el poder y los privilegios de los "dominantes" sobre los "subordinados" (Messner, 1993).

El consumo de ropa deportiva es otra forma de aproximarse al consumo de identidades, "se puede decir que los tejidos, textiles y materiales proporcionan excelentes modelos de conocimiento [...] el mundo es un montón de ropa" (Serres, 1985, p. 82). La ropa permite observar el cambio en la imagen de la mujer a lo largo del tiempo. La página web del Fscclub muestra una serie de fotografías de mujeres boxeando durante diferentes momentos del siglo XX. En ellas se puede apreciar el cambio en las vestimentas de las boxeadoras: de vestidos y pantalones cortos de principio de siglo; pasando por un estilo similar al de los vestidos baño y utilizando tacones en la década de 1930; top, tenis, y pantaloneta pegada durante 1950; y finalmente top, pantaloneta más ancha similar a la masculina, protección obligatoria, tenis y pelo completamente recogido. La evolución de las imágenes muestra un des-cubrimiento del cuerpo de acuerdo a los estándares de hombres y mujeres, y finalmente una inclusión de las mujeres en el deporte que sigue los estándares de seguridad regulatorios.

En lo que respecta al consumo de ropa en el boxeo femenino, en especial en el caso de la indumentaria (vendas y guantes), en el gimnasio al que asisto las mujeres no buscan la mejor tecnología, sino tener prendas más femeninas. La gran mayoría de los guantes y vendas que utilizan son de color rosado, azul claro o dorado. Pocas mujeres utilizan los guantes que regala el gimnasio 9 (grandes y de colores oscuros); esto quiere decir que prefieren gastar más dinero en prendas más exclusivas para diferenciarse y acentuar aún más su papel femenino.

Esta forma de enfatizar la imagen femenina también se puede ver en las campañas publicitarias que promocionan ropa deportiva para mujeres. Uno de los videos de estas campañas resalta la voluntad de las participantes por hacer "lo que ellas quieran", sin que les importe "si es un deporte de hombres o mujeres", ser "duras" y "no ser más unas princesas". Los testimonios de las protagonistas contrastan tanto con el inicio del video, como con el estilo de ropa que se quiere vender: el video comienza con una de las participantes depilándose las cejas, preocupándose por su imagen femenina y muestra a la mayoría boxeadoras utilizando atuendos rosados y ropa ceñida que resalta su figura femenina.

8 En un video del programa Sport Science, la boxeadora Lucía Rijker demuestra que puede golpear más fuerte que un boxeador masculino de su misma altura y peso. Según lo explican en el video, esto se debe a la técnica y aceleración superiores de Lucía. 9 Para complementar este punto, cito uno de mis apuntes etnográficos: "a partir de este año el gimnasio empezó a fabricar guantes rosados para las mujeres inscritas, hasta ahora todas los han preferido sobre los guantes negros. Podría afirmar que las mujeres más interesadas por el boxeo tienden a no tener guantes rosados” (Delgado, comunicación personal, Marzo 2014).

Cuadernos de Antropología 2014, 24(2), 49-72 
Como se ha podido observar, el consumo regula las identidades deportivas femeninas posibles, la "movilidad y la flexibilidad de identificación" que caracterizan la vida del tipo "salir de compras" no son vehículos de emancipación, sino más bien "instrumentos de redistribución de libertades" (Bauman, 2006, p. 97). Brohm va más lejos y habla de "des-sublimación represiva", forma en que las satisfacciones acordadas como el ejercicio corporal son satisfacciones "sustitutas" totalmente integradas en el orden establecido (Brohm, 2001 citado por Esteban, 2013, p. 22).

Pero no todo el consumo de identidades se limita a la oferta existente; se producen también identidades alternativas que buscan una salida al sistema como los "procesos de singularización" que proponen Guattari y Rolnik: "a esa máquina de producción de subjetividad opondría la idea de que es posible desarrollar modos de subjetivación singulares, [...] modos de relación con el otro, modos de producción, modos de creatividad que produzcan una subjetividad singular" (Guattari y Rolnik, 2005, p. 28).

\section{Identidades alternativas y prácticas transgresoras en el deporte femenino}

Las mujeres que practican deportes considerados "masculinos" hacen parte de las "identidades alternativas" porque subvierten el orden imperante que declara a los hombres como únicos participantes legítimos de estas actividades. ¿Qué sucede cuando se enfrentan al sistema, por medio de las prácticas deportivas?

Los deportes "poco femeninos" rompen con el estereotipo de femineidad, y las mujeres que los practican son acusadas de comportarse o moverse de manera "impropia" para la mujer y "caen en conflictos de identidad" (Esteban, 2013, p. 86). Según Esteban (2013), es posible apreciar cómo el cuerpo en el deporte puede representar una estructura asociada con las ideas hegemónicas de masculinidad o femineidad, llevando a las mujeres que practican deportes "masculinos" a ser discriminadas y/o estigmatizadas. De acuerdo con la autora, esta contradicción entre una "identidad femenina que podríamos llamar estándar y la cultura deportiva primordialmente masculina provoca la escasez de mujeres en deportes de competición" (Esteban, 2013, p. 86).

Pero no todo es discriminación, Citro y sus coautoras (2011) introducen el término de "modos alternativos de subjetivación" para explicar que existen ciertas prácticas (en su caso el baile) que promueven "modos alternativos de subjetivación en un contexto multicultural" (Citro et al., 2011, p. 103). El proceso de globalización afecta constantemente la práctica cultural, porque el aumento en el intercambio de todo tipo de bienes ha provocado "la desterritorialización y reterritorialización" de las prácticas culturales. Esto ha generado que "posiciones antes periféricas fueran investidas de nuevas significaciones y legitimidades, transformándolas en valorados bienes culturales, accesibles a sectores sociales más amplios" (Citro et al., 2011, p. 103). 
La práctica del boxeo femenino es un buen ejemplo de este fenómeno: si antes el boxeo era una actividad que sólo practicaban hombres que deseaban convertirse en profesionales; la globalización, el capitalismo y una nueva estética deportiva determinada han logrado no solamente que este deporte se expanda al rededor del globo, sino que cualquiera pueda practicarlo. Por ejemplo en el gimnasio al que asisto, hombres y mujeres pueden inscribirse sin tener que aspirar a convertirse en boxeadores profesionales. En este caso el boxeo se re-significa y se promueve más como una forma de hacer ejercicio y bajar de peso, que como una disciplina ascética y violenta.

Estos procesos pueden desarrollar nuevos tipos de subjetividades alternas al mundo occidental, "cuerpos capaces de pro-mover nuevas formas de subjetivación, que resultan seductoras en la oferta cultural actual" (Citro et al., 2011, p. 105). La película Girlfight ${ }^{10}$ (1999) dirigida por Karyn Kusama retrata la entrada de una mujer latina (subjetividad alterna) al mundo del boxeo. Para Fojas, autora que analiza en detalle la película: "dentro de Hollywood o en la cultura mediática, el espectador tiene poca práctica en ver mujeres de color ejerciendo poder físico y simbólico" (Fojas, 2009, p. 107).

Aunque estas nuevas formas de subjetivación surjan como una propuesta diferente a las ofrecidas por el sistema, deben enfrentarse a los procesos de estandarización característicos de la globalización. El primero que resalta en el boxeo es la dicotomía de los sexos, esta dicotomía masculino/femenino "que contribuye a consolidar matrices simbólicas de desigualdad y prácticas de dominación entre los géneros" (Citro et al., 2011, p. 121). Este dominio puede observarse en las peleas que enfrentan a hombres y mujeres, como la pelea McGregor vs. Chow: “aunque McGregor fue la ganadora incuestionable de la pelea, Chow se llevó el doble de dinero que ella, (...) haciéndolo el verdadero ganador de la batalla entre los sexos” (Fojas, 2009, p. 107).

El segundo es la dicotomía entre individuación y estandarización presente en el nuevo modelo de "belleza interior", "aquella que singulariza y aboga por una individualidad” (Vigarello, 2001, p. 67). A partir de la pregunta que se hace Vigarello apoyándose en este primer principio, se evidencia la contradicción generada por los procesos de globalización: “¿y entonces por qué no volverse gordo para ser bello? porque ser gordo nunca será parte de las normas colectivas de la belleza" occidental (Vigarello, 2001, p. 67). Para el autor, esta es la paradoja de la belleza contemporánea, el individuo se encuentra desgarrado entre lo singular y lo estandarizado.

10 Diana Guzmán, personaje estereotipado de joven agresiva y poco femenina se inicia en el mundo del boxeo. En el gimnasio aprende a boxear al mismo tiempo que se enamora de un joven cubano que entrena allí. El dilema de la película inicia cuando los dos protagonistas deben enfrentarse en combate.

Cuadernos de Antropología 2014, 24(2), 49-72 
No obstante, las mujeres también tienen la posibilidad de subvertir los estereotipos, en la escena en la que Diana pelea con su padre, voltea los paradigmas donde el hombre abusa físicamente de la mujer (como en la película Raging Bull (Scorcese, 1981) cuando Jake La Motta golpea a su mujer), imponiéndose sobre él. Como lo demuestra Butler, "en toda reiteración de una matriz hegemónica siempre existen posibilidades de subversiones y deslizamientos" (citada por Citro et al., 2011, p. 121).

Para Butler la relativa fijeza y perdurabilidad de estas poderosas matrices hegemónicas, como el hecho de que las mujeres no deban o no puedan practicar deportes tradicionalmente "masculinos", "aún en estos ámbitos supuestamente alternativos, dan cuenta de su poder para actuar" (Butler, 2002, p. 41) causando por ejemplo problemas de identidad entre las deportistas. Sin embargo siempre aparece la posibilidad de "rearticularlas o subvertirlas creativamente" (Citro et al., 2011, p. 124), como lo hace Héctor, el entrenador de Diana: "las mujeres tienen un centro de gravedad más bajo, tal vez están más conectadas a tierra... son otro tipo de boxeador" (Héctor en: Kusama, "Girlfight" [filme], 1999) o en palabras de un entrenador: "las mujeres no tienen la misma fuerza que los hombres, pero son boxeadoras mucho más técnicas" (Llerena, comunicación personal, febrero, 2014).

En esta segunda sección se ha podido observar cómo el capitalismo se ha ido expandiendo mediante un sistema de "identidades porosas", abarcando todos los estilos deportivos. El cuerpo se ha convertido en un símbolo de este sistema, promocionado por los medios, regulado por el consumo y mercantilizado en forma de producto. Pero, no todo es tragedia, existen identidades alternativas al sistema capitalista que "a pesar de propagar elementos de significación de la ideología dominante, y a pesar de ser prisioneras de numerosos sistemas de modelización, expresan en un cierto nivel inconsciente, $[\ldots]$ un «vector de revolución molecular» ${ }^{11}$ " (Guattari y Rolnik, 2005, p. 86), un deseo por levantarse contra el orden hegemónico. En la última parte de este trabajo, se presentará una forma de rearticular la manera en la que se ha estudiado la corporalidad, por medio de una perspectiva de "adentro hacia afuera", donde la experiencia vivida adquiere un papel central.

\section{Cuerpo individual: La incorporación de la experiencia vivida}

Algunos estudios sobre las mujeres y el deporte tienden a olvidar que el cuerpo tiene un papel activo ligado al pensamiento y a los sentidos. La relación subjetiva de cada individuo con su cuerpo también lo lleva a generar nuevos conocimientos, nuevas prácticas y formas de resistencia. Este último apartado presentará cómo aprende y cómo se comunica el cuerpo, generando nuevos conocimientos. También se introducirá el concepto de embodiment y algunos trabajos que asumen esta perspectiva.

11 Mientras que las revoluciones tradicionales se dan a nivel de individuos y grupos, Guattari y Rolnik (2005) definen la revolución molecular como un estado preindividual e inconsciente que pone en juego el deseo más que la necesidad. 


\section{El cuerpo como fuente de conocimiento}

En su artículo The body's career in Anthropology, Csordas señala que hay dos formas de comprender el cuerpo: "puede ser una fuente de representación, o un motivo de estar en el mundo" (Csordas, 2000 , p. 184). Foucault (1986), uno de los defensores de la primera propuesta, argumenta que la cultura no se manifiesta únicamente en los objetos y las representaciones, también lo hace en la percepción del cuerpo (citado en Csordas, 2000, p. 183). Esta forma de aproximarse al cuerpo es la que se desarrolló en la primera y segunda sección del trabajo, adoptando perspectiva externa que observa y analiza las representaciones del cuerpo.

El segundo enfoque, que se expondrá en la presente sección, considera al cuerpo como un motivo de estar en el mundo, y nace a partir de los trabajos del filósofo francés Merleau-Ponty. Contrario al pensamiento de Descartes, donde el alma se escinde del pensamiento, el filósofo francés argumenta que "no hay pensamiento que no pase por los sentidos" (Merleau-Ponty, 1945; citado en Csordas, 2000, p. 183). Autores como Serres (1985) han retomado y continuado con esta línea de pensamiento, como aproximación crítica de la modernidad.

Aunque es importante reconocer que hay un componente cultural en la manera de interpretar y hacer uso de los conocimientos del cuerpo, también es posible afirmar que el conocimiento corporal difiere del conocimiento intelectual; para esto, se puede argumentar en primer lugar que la inteligencia del cuerpo no se basa en la razón, sino en el conocimiento directo del mundo. Según Sachs (2001), la diferencia más evidente es la inmediatez y la cercanía de la percepción sensorial inicial; en segundo lugar, como el conocimiento no es conceptual o verbal, no es inhibido por las contradicciones, y además puede reconocer muchos significados a la vez: su inteligencia es polisémica. Y en tercer lugar, "el conocimiento del cuerpo no depende de signos para interpretar el conocimiento" (Sachs, 2001, p. 112).

Acogiendo este argumento desde la perspectiva femenina, se puede decir que la mujer no solo "su-

fre" la estructura social, ya que su cuerpo también es fuente esencial de aprendizaje. A diferencia de otras formas de instrucción que constriñen a la mujer, en el deporte las mujeres aprenden por sí mismas, lo que pueden hacer con su propio cuerpo. El deporte "facilita la concentración; enseña sobre el trabajo riguroso y continuo; contribuye al trabajo en equipo y a respetar las reglas del juego" (Serres, 2011, p. 51). Las actividades físicas constituyen una fuente básica de aprendizaje corporal, motriz e individual.

Por ejemplo, en un estudio dirigido por Löckman (2011), alrededor de la práctica femenina del Tomiki Aikido, se encontró que un gran avance ocurrió cuando las mujeres de su clase se dieron cuenta que la energía del cuerpo no la hacen necesariamente los músculos fuertes, ya que las técnicas de este deporte ponen énfasis en el equilibrio, el ritmo y la flexibilidad. Esta nueva disposición corporal "desafía la imagen social del cuerpo femenino débil” (Löckman, 2011). 
No hay nada en el conocimiento que no haya estado primero en todo el cuerpo, constata Serres (2011) en su libro, utilizando como ejemplo el descubrimiento de Arquímedes en su tina. En el deporte el individuo incorpora nuevos saberes a su mundo, lo que le permite reproducir movimientos específicos y leer los movimientos de su adversario, planeando a partir de esta información un movimiento de contra-ataque.

El ejemplo de esta teoría sobre cómo aprende el cuerpo se puede leer en la etnografía, sobre el boxeo publicada en 1989 por Wacquant. Según el aprendiz de boxeador, "el dominio teórico sirve de poco mientras el gesto no haya quedado grabado en el esquema corporal; y sólo una vez asimilado el golpe con y por el ejercicio físico repetido hasta la náusea, queda completamente claro para el intelecto" (Wacquant 2000, p. 75). En el entrenamiento de boxeo se enseña la técnica del deporte y a partir de ahí se aprenden los esquemas que permiten diferenciar, evaluar y reproducir la técnica.

Frente a estos trabajos etnográficos y descripciones sobre la técnica, Samudra se pregunta cómo traducir la experiencia kinésica en conocimiento, ya que existen conceptos que representan la experiencia "a costa de dejar un montón no dicho" (Jackson, 1995; citado por Samudra, 2008, p. 72). Conocer la estructura del movimiento no es lo mismo que experimentar la sensación del movimiento. Con base en estos problemas de transcripción la autora propone "traducir la experiencia Kinésica y sus implicaciones en el momento en el que las acciones del cuerpo se conviertan en memoria corporal" (Samudra, 2008, p. 67), teniendo en cuenta que la experiencia es sinónimo de subjetividad. A esta propuesta Wacquant añadiría que una de las alternativas para transcribir este tipo de experiencias es cambiando la forma de escribir, mezclando estilos según el propósito. Así, al texto analítico le correspondería un estilo sociológico; al etnográfico una escritura descriptiva; y al experiencial una narración literaria (Wacquant, 2013).

Finalmente, "saber es olvidar" (Serres, 2011, p. 83), las posturas se incorporan en los músculos más rápido de lo que las comprendemos, de una manera casi inconsciente. Posiblemente ésta es una de las causas que explican por qué el cuerpo ha sido relegado a la posición de agente pasivo. La literatura alrededor del tema parece haber olvidado que el cuerpo es la herramienta principal de conocimiento y también ha omitido que el cuerpo tiene diferentes maneras de comunicarse, porque la mayoría han sido relegadas por el lenguaje.

\section{El cuerpo se comunica}

Existe una jerarquización de habilidades en función del lenguaje cuyo objetivo final es demostrar que "el discurso (lenguaje hablado o escrito) es todo lo que realmente necesitamos" (Serres, 1985, p. 193). Por ejemplo, el medio preferido para transmitir o evaluar el conocimiento es el lenguaje escrito, demeritando otras formas de expresión. Sumado a esto, el autor afirma que las acciones del cuerpo se pierden en la escritura cuando los movimientos complejos y rigurosos se convierten en simples verbos que no logran transmitir la totalidad del movimiento (Serres, 1985). Si el lenguaje cohíbe u oculta las acciones del cuerpo, es necesario buscar una alternativa, una nueva forma de comunicarse y de estudiar los movimientos corporales. 
La "proxémica" es el término es el término empleado por Hall en 1963 y retomado por Le Breton para describir el empleo y la percepción que el ser humano hace de su espacio físico y de su intimidad personal. La distancia social cambia dependiendo de la cultura, el grado de familiaridad y el objetivo del individuo. Según los dos autores, si "la distancia normativa es franqueada el intercambio pierde su neutralidad" (Le Breton, 1999, p. 127). Este es un concepto que se podría utilizar para el análisis de los deportes de contacto, ya que la distancia entre los adversarios está reglamentada. Si bien los boxeadores se sitúan en otro nivel de intercambio como lo es el intercambio violento, también deben respetar la "neutralidad" de las reglas de juego. En el "re-match" contra Evander Holyfield, el boxeador Mike Tyson quebró este límite arrancándole un pedazo de oreja a su contrincante, acto que lo llevó a ser descalificado de la pelea.

Otra forma de estudiar el lenguaje corporal, sobre todo en el ámbito deportivo, es por medio de la Kinésica como lo propone la autora Buñuel (1991). La Kinésica "es donde el cuerpo se estudia como contexto de la comunicación. Los movimientos y gestos corporales adoptan formas y estructuras determinadas culturalmente, fruto de un aprendizaje social" (Buñuel, 1991, p. 112). A partir de una investigación que utiliza la Kinésica como método de estudio, la autora afirma que existen dos modelos que rigen la práctica del ejercicio: el "instrumental" y el "relacional".

En el primer modelo predomina la voluntad de actuar sobre uno mismo y de alcanzar el éxito personal: "es el modelo tradicional masculino, pero que para las mujeres supone una gran novedad y la entrada a un mundo público", como el de las gimnasias de forma (Buñuel, 1991, p. 112); en contraste, en el modelo "relacional" prima el aspecto lúdico del deporte y "el deseo de construir espacios de comunicación opuestos a una lógica instrumentalista” (Buñuel, 1991, p. 115).

Contrario a las secciones uno y dos de este balance bibliográfico, lo que se ha expuesto en estos dos primeros acápites cuestiona el hecho de que el cuerpo sea un simple receptor de normas y modas. Todo lo contrario, el cuerpo ocupa un lugar central en la creación de conocimiento, puesto que todo aprendizaje pasa primero por los sentidos.

\section{Embodiment: el aprendizaje del cuerpo puesto en práctica}

Considerando la "dimensión carnal de la existencia" (Wacquant, 2000, p. 11), este capítulo se dedicará a presentar investigaciones que incluyen "la incorporación del cuerpo vivido" o embodiment como propuesta de estudio. Este concepto funciona bajo el principio de "vivir la experiencia para comprenderla" (Csordas, 2000, p. 15), lo cual implica un cambio de perspectiva en los estudios del cuerpo.

Algunos de los trabajos que utilizan el embodiment como metodología son realizados por autores que se han licenciado en educación física o que practican algún deporte con intensidad. Aunque las Ciencias Sociales se han separado de las Ciencias Deportivas (probablemente debido a su tecnificación y obsesión 
por la productividad), es necesario observar que los aportes recientes en los estudios del cuerpo y el deporte parten de investigaciones que incorporan la práctica participativa durante sus investigaciones.

Mora, se introduce en el mundo de la danza (ballet) para observar la construcción del cuerpo y las subjetividades durante las trayectorias de formación de las alumnas. En su artículo, la autora explica cómo en un grupo social determinado: "las experiencias y las representaciones son dos instancias que se articulan y se relacionan dialécticamente" (Mora, 2010, p. 220). La experiencia se construye en relación con las categorizaciones; y al mismo tiempo las experiencias refuerzan las representaciones sociales disponibles, las re-estructuran o las transforman; afirmación que también comparten las autoras Citro et al. (2011) y Butler (2002).

El artículo de Mora también nos permite comparar el ballet y el boxeo. Las descripciones del entrenamiento que hace Wacquant (2000) en su etnografía y las que hace Mora en su artículo, resultan muy similares. Oates también resalta esta idea en sus textos: "a semejanza del bailarín, un boxeador "es" su cuerpo, y está totalmente identificado con él" (Oates, 1987, p. 19). El tipo de trabajo y el nivel de exigencia son los mismos; sin embargo, como se ha visto anteriormente los medios se han enfocado en demostrar que las mujeres no pueden boxear debido a su condición de "sexo débil".

Este estereotipo también tiene consecuencias observables en otras prácticas de combate. Por ejemplo Schneider (2010), practicante de Kalaripayatu (arte marcial) descubrió en el curso de su etnografía que ella no estaba recibiendo una enseñanza real por parte de su entrenador debido a su condición de mujer. En mi caso sucede algo similar, durante el año que llevo entrenando diariamente en el gimnasio de boxeo, de los catorce profesores que he tenido, solo cuatro de ellos decidieron enseñarme la técnica del boxeo. Uno de ellos era una mujer ${ }^{12}$ y el otro era Tom, un boxeador aficionado inglés que asistía al gimnasio, lo que quiere decir que hasta ahora solo dos de los entrenadores del gimnasio se han propuesto enseñarme a boxear realmente. Los otros profesores enseñaban únicamente a los hombres mientras que a las mujeres las ponían a hacer ejercicios para mejorar su físico, sin importar si aprendían la técnica o no.

Mennesson y Clément (2009) hacen uso del embodiment, las entrevistas y la observación para dar cuenta de las prácticas corporales de las mujeres en el boxeo soft y hard ${ }^{13}$. Los resultados de esta investigación muestran que las mujeres clasificadas como "soft" reproducen la imagen estereotipada de la mujer; mientras que las boxeadoras hard, comprometidas profesionalmente, construyen "una identidad alternativa,

12 Para complementar esta idea, cito una de mis notas durante el trabajo de campo: "Adriana es la entrenadora que nos ha exigido más físicamente y también es la primera entrenadora en corregirme y enseñarme bien los movimientos de defensa y ataque. Me ha subido al ring varias veces y me ha puesto a pelear contra muchos hombres" (Delgado, comunicación personal, 2013).

13 En Francia se distinguen dos (2) tipos de boxeo, el "hard" y el "soft": el "hard" es la continuidad del boxeo inglés; el "soft" es el boxeo francés de Savat el cual incluye manos y pies y se enfoca más en mostrar la técnica que en pegar duro. 
desviada de las expectativas sociales que rodean la femineidad" (García y Spencer, 2013, p. 9). En este artículo, los autores se enfocan particularmente en las boxeadoras hard cuya práctica es "simbólicamente asociada a lo masculino". Su objetivo es demostrar que "la interiorización de la dominación masculina es particularmente eficaz” en este caso (Mennesson y Clément, 2009, p. 77).

Como se había mencionado, la inscripción de las mujeres en este tipo de deportes amenaza "el grupo juramentado" de los hombres en su propio terreno, ya que cuestiona los atributos "exclusivamente" masculinos y pone en peligro el dominio del patriarcado. Por lo tanto, la discriminación por ser débiles o por ser poco femeninas no se hace esperar. Las mujeres deben preocuparse por su aprendizaje de la misma forma que los hombres, y además las presiones sociales las obligan a "preocuparse en forma simultánea por el trabajo de feminización corporal” (Mennesson y Clément, 2009, p. 77).

Según los autores, hay una exigencia de femineidad por parte de los miembros del gimnasio, del público y de ellas mismas, lo cual trae como consecuencia la "interiorización de la dominación masculina" (Mennesson y Clément, 2009, p. 84). En el gimnasio, por ejemplo, las mujeres deben adaptarse al entrenamiento de los hombres, perpetuando las formas de entrenamiento varoniles. Estas maneras de entrenar pensadas desde y para los hombres "favorecen el desarrollo de la potencia física, lo cual se ve reflejado en un cambio corporal” (Mennesson y Clément, 2009, p. 84).

Paradójicamente, a partir de los cambios corporales que impulsan los entrenamientos, viene la segunda forma de discriminación: los boxeadores no aceptan que las mujeres parezcan hombres por su físico, su ropa o su comportamiento. En consecuencia "las mujeres se niegan a llevar camisas sin mangas con el objetivo de ocultar sus brazos demasiado musculosos para una mujer" (Mennesson y Clément, 2009, p. 84). Uno de los casos que lleva al extremo este tipo de discriminación en América latina se ha presentado contra la boxeadora y campeona panameña Ana Pascal, debido a su apariencia supuestamente masculina, en países como "Colombia, Nicaragua, Curazao, ha tenido que someterse a exámenes médicos para comprobar que es mujer. 'Nací mujer, soy mujer', repite ella” (Ortiz, 2007, p.1).

La importancia de la imagen femenina para las boxeadoras también se puede apreciar en los combates. Las mujeres entran y salen de su camerino maquilladas, esto para demostrar que "no porque se boxea se es hombre" (Mennesson y Clément, 2009, p. 85). En este caso las boxeadoras se rigen por el principio que promulgan los medios: las mujeres pueden practicar deportes mientras no pierdan su femineidad.

Aunque Mennesson y Clément (2009) no desarrollan a profundidad este tema en el caso de las boxeadoras hard, la familia también juega un rol muy importante, rechazando la falta de femineidad de sus hijas boxeadoras: "mi familia me dejó de hablar (cuando comencé a boxear), la única que me apoyó fue mi mamá" (Arias, comunicación personal, agosto, 2013). Esta falta de apoyo puede derivar más adelante en los problemas de identidad a los que hace alusión Esteban (2013) en sus investigaciones. 
Al final del artículo los autores concluyen que en este caso "el uso de la violencia física va acompañado de una devaluación de la mujer y de una denigración de la mujer, a través de una dominación masculina exacerbada" (Mennesson y Clément, 2009, p. 91). Esta conclusión se puede ejemplificar a partir de las preguntas que los autores hacen a las boxeadoras sobre la división del trabajo doméstico:

...las mujeres boxeadoras entrevistadas se responsabilizan de todas las tareas domésticas y reivindican este tipo de repartición con el objetivo de no devaluar más su imagen femenina "a mi gusta hacerlo, porque algunas veces oigo a la gente decir: ella boxea debe ser un desorden (Mennesson y Clément, 2009, p. 87).

Esta última sección ha mostrado como "la incorporación del cuerpo vivido" ha traído una nueva perspectiva a los estudios sobre el cuerpo y el deporte, especialmente en el caso de las mujeres. Este enfoque cuestiona la idea de las inequidades de género como principio natural y muestra que las imposiciones de género son sólo efectos históricos que se incorporan en el cuerpo (McCaughey, 1998, p. 295). A diferencia de otras formas de investigación que se fijan exclusivamente en las representaciones, el embodiment muestra como los cuerpos absorben, sufren, reestructuran o reinventan estas representaciones a partir de la experiencia.

\section{Conclusiones}

A lo largo de este balance bibliográfico se han presentado diferentes teorías, conceptos y estudios de caso que abordan el tema corporal en el deporte, y más específicamente el de las mujeres en el boxeo. Desde la perspectiva del cuerpo político, se trabajó un tema poco estudiado por la literatura académica: las regulaciones deportivas impuestas al cuerpo de las mujeres que han impedido su participación plena en el boxeo. En esta sección también se pudo observar el poder de la estructura sobre el individuo, ya que además de las reglas explícitas, existen reglas implícitas que controlan el comportamiento de las boxeadoras dentro del ring.

Desde el punto de vista del cuerpo social, esfera un poco más desarrollada por la literatura, se trabajó alrededor del consumo de identidades donde se mostró como el comercio construía y regulaba las representaciones deportivas de las mujeres, explotando la femineidad como requisito obligatorio en cualquier deporte. Así mismo, se expuso una nueva corriente de trabajos académicos que busca investigar prácticas alternativas y transgresoras del orden global donde las mujeres a pesar de recibir imposiciones de la estructura, subvierten el orden de una manera creativa.

Por último, el enfoque a partir del cuerpo individual, hizo énfasis en el poder de la "experiencia vivida" como fuente de conocimiento, comunicación, e investigación. Aunque en un principio se trabajó esta aproximación desde un aspecto más teórico, se descubrieron nuevas ramas como la "proxémica" y 
la "kinésica", conceptos que podrían ser útiles en una futura investigación que haga uso del embodiment. Para finalizar, se presentaron algunos estudios que utilizaban como herramienta de investigación la incorporación de la "experiencia vivida", mostrando un punto de vista diferente sobre los estudios del cuerpo. Aunque esta perspectiva expone nuevas herramientas para abordar el tema corporal y revindica al cuerpo como fuente de conocimiento y liberación; en el caso de Mennesson y Clément (2009), practicar un deporte tradicionalmente "masculino" no lleva al empoderamiento de la mujer, sino a la sumisión eficaz frente a las normas patriarcales. El cuerpo en este caso no es un medio de liberación, sino una herramienta más de coerción. Sería interesante en futuros estudios comparar este fenómeno en distintos contextos culturales y observar si el mismo comportamiento se replica, o si existen casos donde el boxeo tenga un efecto positivo en la autoestima corporal de las mujeres.

Partiendo de los hallazgos hechos en esta revisión de literatura al rededor del tema del deporte y el cuerpo, en especial del boxeo practicado por mujeres, se propone para futuras investigaciones enfocar la investigación en lo que puede aprender una mujer por medio del deporte y a través de su cuerpo; y no en una única perspectiva que refleje solamente las inequidades de la estructura. Mientras que el análisis desde el cuerpo permite presentar nuevos puntos de vista, problemas y estrategias de resistencia creativa, los trabajos que parten únicamente de las representaciones solo pueden reproducir y perpetuar la estructura social. No se trata de hacer nuevos estudios sino de abordarlos de una forma diferente, a partir de la experiencia y la subjetividad (Csordas, 2000, p. 189). En el caso del boxeo, son necesarios enfoques que además de mostrar las inequidades del mundo pugilístico hacia las deportistas, resalten la corporalidad de las boxeadoras desde su propio punto de vista de "mujeres mal-criadas", que tienen la capacidad de amenazar los órdenes establecidos como "naturales".

\section{Referencias bibliográficas}

Amorós C. (2008). Mujeres e imaginarios de la globalización, Reflexiones para una agenda teórica global del feminismo. Buenos Aires: Homo Sapiens Ediciones.

Anónimo (1925). La mujer sube al ring. Patria. Revista de Ideas, III(69), 27.

Bankowsky, K. (Directora) (1999). Shadow Boxers [Documental]. USA: Bankowsky.

Bauman, Z. (2006). Modernidad líquida. Buenos Aires: Fondo de Cultura Económica.

Bauman, Z. (2007). Vida de consumo. México D.F.: Fondo de Cultura Económica.

Besnier, N. y Brownell, S. (2012). Sport, modernity and the body. Annual Review of Anthropology, 41, 443459. DOI: 10.1146/annurev-anthro-092611-145934

Buñuel, A. (1991). La construcción social del cuerpo de la mujer en el deporte. Reis, 68/69, 99-117.

Burnett, C. (2001). Whose game is it anyway? Power, play and sport. Agenda, 49, 71-78.

Butler, J. (2002). Cuerpos que importan. Paidós: Buenos Aires.

Buysse, J. A. y Sheridan, M. (2004). Construction of gender in sport: An analysis of intercollegiate media guide cover photographs. Gender and Society, 18(1), 66-81.

Cuadernos de Antropología 2014, 24(2), 49-72 
Castañeda M. P. (2009). En torno a la construcción del cuerpo femenino desde la concepción católica del mundo, un enfoque antropológico feminista. En M. Aguilar \& P. Lazo (eds), Corporalidades (pp. 333-365). México DF: Centro de Investigaciones Interdisciplinarias en Ciencias y Humanidades (CEIICH)-UNAM/ Universidad Iberoamericana.

Citro, S., Aschieri, P. y Mennelli, Y. (2011). El multiculturalismo en los cuerpos y las paradojas de la desigualdad poscolonial. Boletín de Antropología Universidad de Antioquia, 25(42), 102-128.

Csordas, T. J. (2000). The body's career in Anthropology. En H. Moore (ed.), Anthropological theory today (pp. 172-205). Cambridge: Polity Press.

Douglas, M. (1966). Purity and danger. London: Routledge and Kegan Paul.

Eichberg, H. (2009). Body culture. Physical Culture and Sport Studies and Research, XLVI, 79-98. DOI: 10.2478/v10141-009-0006-0

Esteban, M. (2013). Género, itinerarios corporales, identidad y cambio. España: Ediciones Bellaterra.

Ezzell, M. B. (2009). Barbie dolls on the pitch: Identity work, defensive othering, and inequality in women's rugby. Social Problem, 56(1), 111-131.

Filina (1923). Las mujeres y el atletismo. El gráfico, (XV)703, 19.

Fojas, C. (2009). Sports of spectatorship: Boxing women of color in "Girlfight" and beyond. Cinema Journal, 49(1), 103-115.

Foucault, M. (1986). Vigilar y castigar. Madrid: Siglo XXI Editores.

García, R. y Spencer D. (2013). Fighting scholars: Habitus and ethnographies of martial arts and combat sports. New York: Anthem Press.

Geertz, C. (1973). The interpretation of cultures. New York: Basic Books.

Guattari, F. y Rolnik, S. (2005). Micro política, cartografias del deseo. Petrópolis: Editora Vozes Ltda.

Gumbrecht, H. (2006). In praise of athletic beauty. Massachusetts: Belknap Press.

Gutiérrez, R. (1923). Mis ideas sobre el sport. Periódico el Gráfico, (XIII)644, 702.

Guttman, A. (1991). Women's sports a history. New York: Columbia University Press.

Hanson, S. L. y Kraus, R. (1998). Women, sports, and science: Do female athletes have an advantage?. Sociology of Education, 71(2), 93-110.

Huerta, F. (2010). A todos los que quieren y aman el Juego del hombre, la deportivización del cuerpo masculino. En M. Aguilar y P. Lazo (eds), Corporalidades (pp. 301-333). México DF: Centro de Investigaciones Interdisciplinarias en Ciencias y Humanidades (CEIICH)-UNAM/ Universidad Iberoamericana.

Kusama, K. (Director) (1999). Girlfight [película]. New Jersey: Independent film Chanel. 2000.DVD.

Le Breton, D. (1999). Las pasiones ordinarias: Antropología de las emociones. Buenos Aires: Nueva Visión. Löckman, P. (2011). Becoming aware of gender embodiment: female beginners learning Aikido. En E- 
Kennedy y P. Markula (eds), Women and exercise: The body, health and consumerism (pp. 266-279). London: Routledge.

Mauss, M. (1995). Les techniques du corps. En M. Mauss, (Ed.), Sociologie et Anthropologie (pp. 363-86). Paris: Press Univ. France.

McCaughey, M. (1998). The fighting spirit: Women's self-defense training and the discourse of sexed embodiment. Gender and Society, 12(3), 277-300.

Mennesson C. y Clément, P. (2009). Boxer comme un homme, être une femme. Actes de la Recherche en Sciences Sociales, 4(179): 76-91. DOI: 10.3917/arss.179.0076

Merleau-Ponty, M. (1945). Fenomenología de la percepción. Paris: Gallimard.

Messner, M. A. (1993). Separating the men from the girls: The gendered language of televised sports. Gender and Society, 7(1), 121-137.

Mora, A. S. (2010). Entre las zapatillas de punta y los pies descalzos: Incorporación, experiencia corporizada y agencia en el aprendizaje de danza clásica y contemporánea. En M. Aguilar y P. Lazo (eds), Corporalidades (pp. 301-333). México DF: Centro de Investigaciones Interdisciplinarias en Ciencias y Humanidades (CEIICH)-UNAM/ Universidad Iberoamericana.

Oates, J. C. (2013). Del boxeo. Bogotá: Ediciones Prisa.

Ortiz, M. P. (2007). La boxeadora panameña Ana Pascal es la nueva 'Mano de piedra' y no tiene quién le gane. [Versión de El tiempo]. Recuperado de http://www.eltiempo.com/archivo/documento/CMS3500741

Pedraza, Z. (1999). En cuerpo y alma: Visiones del progreso y la felicidad. Universidad de los Andes: Colombia.

Reischer, E. y Koo, K. S. (2004). The body beautiful: Symbolism and agency in the social world. Annual Review of Anthropology, 33, 297-317.

Sachs, R. (2001). Embodiment and community. Western Folklore, 60(2/3), 111-124.

Salcedo, A. (2012). El oro y la oscuridad: la vida gloriosa y trágica de Kid Pambelé. Colombia: Ediciones Prisa.

Samudra, J. K. (2008). Memory in our body: Thick participation and the translation of kinesthetic experience. American Ethnologist, (35)4, 665-681. DOI: 10.1111/j.1548-1425.2008.00104.x

Sánchez, R. y Spencer, D. (2013). Introduction: Carnal ethnography as path to embodied knowledge. En R. Sánchez y D. Spencer (eds), Fighting scholars: Habitus and ethnographies of martial arts and combat sports (pp. 1-18). New York: Anthem Press.

Scorcese M. (Director) (1981). Ragging bull. California: United Artist.

Scheper-Hughes, N. y Lock, M. (1987). The mindful body: A prolegomenon to future work in medical Anthropology. Medical Anthropology Quarterly, 1(1), 6-41. 
Serres, M. (1985). The five senses: A philosophy of mingled bodies. Great Britain: MPG Books.

Serres, M. (2011). Variaciones sobre el cuerpo. México D.F.: Fondo de Cultura Económica.

Schneider, S. (2010). Learning India's martial art of Kalarippayattu: Unsettled ecologies of gender, class, culture, and ethnicity. Journal of Asian Martial Arts, 2(5), 45-62.

Vigarello, G. (2001). Corregir el cuerpo. Buenos Aires: Nueva Visión.

Wacquant, L. (2000). Entre las cuerdas: Cuadernos de aprendiz de boxeador. Argentina: Siglo XXI editores. Wacquant, L. (2013). Habitus as topic and tool: reflections on becoming a prizefighter. En R. Sánchez y D. Spencer (eds), Fighting scholars: Habitus and ethnographies of martial arts and combat sports (pp. 19-32). New York: Anthem Press. 